The University of San Francisco

USF Scholarship: a digital repository @ Gleeson Library |

Geschke Center

Kinesiology (Formerly Exercise and Sport Science)

College of Arts and Sciences

2008

\title{
Gender Differences in Lower Limb Frontal Plane Kinematics During Landing
}

Gerwyn Hughes

University of San Francisco, ghughes@usfca.edu

James Watkins

Nick Owen

Follow this and additional works at: https://repository.usfca.edu/ess

Part of the Sports Sciences Commons, and the Sports Studies Commons

\section{Recommended Citation}

Hughes, Gerwyn; Watkins, James; and Owen, Nick, "Gender Differences in Lower Limb Frontal Plane Kinematics During Landing" (2008). Kinesiology (Formerly Exercise and Sport Science). 36.

https://repository.usfca.edu/ess/36

This Article is brought to you for free and open access by the College of Arts and Sciences at USF Scholarship: a digital repository @ Gleeson Library | Geschke Center. It has been accepted for inclusion in Kinesiology (Formerly Exercise and Sport Science) by an authorized administrator of USF Scholarship: a digital repository@ Gleeson Library | Geschke Center. For more information, please contact repository@usfca.edu. 
1 Title: $\quad$ Gender differences in lower limb frontal plane kinematics during landing.

Keywords: ACL Injury, gender differences, kinematics, landing, volleyball.

List of authors and institutions.

Corresponding author: Gerwyn Hughes.

Postal Address:

Health and Exercise Sciences Group,

Thames Valley University,

Wellington Street,

Slough,

UK.

SL1 1YG.

gerwyn.hughes@tvu.ac.uk

$+441753697532$

Gerwyn Hughes ${ }^{1}$ James Watkins ${ }^{2}$ and Nick Owen².

Institutions: ${ }^{1}$ Faculty of Health and Human Sciences,

Thames Valley University,

Slough, UK.

${ }^{2}$ Department of Sports Science,

Swansea University,

Swansea, UK, 


\section{Abstract.}

The study aimed to investigate gender differences in knee valgus angle and interknee and inter-ankle distances in university volleyball players when performing opposed block jump landings. Six female and six male university volleyball players performed three dynamic trials each where subjects were instructed to jump up and block a volleyball suspended above a net set at the height of a standard volleyball net as it was spiked against them by an opposing player. Knee valgus/varus, interknee distance and inter-ankle distance (absolute and relative to height) were determined during landing using 3D motion analysis. Females displayed significantly greater maximum valgus angle and range of motion than males. This may increase the risk of ligament strain in females compared with males. Minimum absolute interknee distance was significantly smaller in females and absolute and relative interknee displacement during landing was significantly greater in females compared with males. Both absolute and relative inter-ankle displacement during landing was significantly greater in males than females. These findings suggest that the gender difference in the valgus angle of the knee during two-footed landing is influenced by gender differences in the linear movement of the ankles as well as the knees. Coaches should therefore develop training programmes to focus on movement of both the knee and ankle joints in the frontal plane in order to reduce the knee valgus angle during landing which in turn may reduce the risk of non-contact ACL injury. 


\section{Introduction.}

Anterior Cruciate ligament (ACL) injury is a common injury and approximately $70 \%$ these injuries occur in sport (Faegin, 1988; Johnson, 1988; Smith et al., 1988). ACL rupture is a debilitating injury and can cause long-term absence from participation in a sport and, in some cases, enforced retirement. Between $70 \%$ and $90 \%$ of $\mathrm{ACL}$ injuries have been reported to be non-contact in nature, i.e., no direct contact with the knee at the time of injury (Woodland and Francis, 1992; McNair et al., 1993; Mykelbust et al., 1997; Griffin et al., 2000). The incidence on non-contact ACL injury in females has been reported to be 6 to 8 times greater than in males competing in the same sports (Chandy and Grana, 1985; Gray et al., 1985; Ferretti et al., 1992; Paulos, 1992; Malone et al., 1993; Lidenfeld et al., 1994; Arendt and Dick, 1995; Gwinn et al., 2000).

Non-contact ACL injuries appear to be common in activities involving landing (Hume and Steele; 1997, Otago and Neal; 1997), deceleration (Miller et al., 1995) and rapid change of direction (Bartold, 1997). The incidence of ACL injury is therefore relatively high in sports such as basketball, netball, handball and volleyball that are characterised by a high frequency of landing, decelerating and rapid changes of direction (Arendt and Dick, 1995; Griffin et al., 2000).

Whilst the muscle moments about the joints of the lower limbs largely determine the movement patterns of the lower limbs, the resulting angular kinematics may provide some indication of the strain on the joint ligaments. The greater the range of 
abnormal joint movement (movement outside a joint's normal range of motion), the greater the possibility of strain on associated ligaments (Watkins, 1999). ACL injury is often associated with valgus movement of the knee at the time of injury (Boden et al., 2000; Olsen et al., 2004). For example, Olsen et al. (2004) analysed videotapes of game situations in which ACL injury occurred in team handball in order to identify the mechanisms for ACL injury. Three physicians were used to identify factors relating to the knee position such as estimated varus-valgus angle. The results showed that the knee was in a valgus position in all of the 20 cases analysed and the estimated valgus angle was above $10^{\circ}$ in 19 of the 20 cases. Therefore it was concluded that valgus knee movement is a high risk factor for ACL injury.

Since increased valgus angle during dynamic movement has been associated with an increased likelihood of ACL injury a number of studies have investigated the frontal plane kinematics of the knee during landing/cutting. These studies report that females tend to exhibit greater maximum knee valgus angle and greater range of motion (from initial contact to maximum) when landing/cutting than males (Malinzak et al., 2001; Ford et al., 2003; Kernozek et al., 2005). Consequently, the reported greater maximum knee valgus angle in females when landing may increase the risk of $A C L$ injury relative to males. However, the valgus angle of the knee is related to the linear movement of the knee and ankle joints. At present there is little knowledge of the relative contribution of the linear movements of the knee and ankle joints to the reported greater valgus angle in females compared with males during landing. During a two-footed landing manoeuvre, the distances between corresponding joints in the right and left leg, i.e., distance between right and left knees, (inter-joint distances) may provide more insight into the influence of the linear movements of the knee and 
ankle joints on the increased valgus angle of the knee in females than looking at the knee joint in isolation.

Aim.

The aim of the study was to investigate the effects of gender on knee valgus angle and inter-knee and inter-ankle distances in university volleyball players performing block jump landings.

\section{Methods.}

Subjects.

Data were obtained for six male (Mean age $21.6 \pm 3.3$ years, mass $70.1 \pm 3.1 \mathrm{~kg}$ and height $175.7 \pm 8.6 \mathrm{~cm}$ ) and six female (Mean age $21.2 \pm 1.3$ years, mass $57.6 \pm 7.5$ $\mathrm{kg}$ and height $164.8 \pm 7.5 \mathrm{~cm}$ ) university volleyball players. All subjects were right leg dominant and had no previous history of hip/knee or ankle injury. Written consent forms approved by the departmental ethics committee were signed by all subjects prior to data collection.

\section{Measurement system.}

Two adjacent AMTI force platforms embedded into the laboratory floor sampling at $600 \mathrm{~Hz}$ were used to measure ground reaction force to determine initial ground contact of right and left legs on landing. A 12 camera Vicon 512 system (Vicon, Oxford, England) sampling at $120 \mathrm{~Hz}$ was used to determine 3D coordinates of 16 retro-reflective markers (25 $\mathrm{mm}$ diameter). Markers were placed directly on the skin 
over anatomical landmarks in accordance with the Vicon system's lower body plug-in gait marker set; right and left anterior superior iliac spines, right and left posterior superior iliac spines, lower lateral surface of the right and left thigh along the line between the hip and knee joint markers, right and left lateral epicondyle the femur, lower lateral surface of the right and left tibia along the line between knee and ankle joint markers, right and left lateral malleolus, superior proximal end of the second metatarsal of the right and left foot, posterior aspect of the Achilles tendon of the left and right leg at the same height as the second metatarsal marker. From the location of the markers placed on the body, combined with required anthropometric measurements (height, weight, leg length, knee width and ankle width) of each subject, the Vicon system calculated the 3D coordinates of hip, knee and ankle joint centres which were used to determine the thigh and shank segment local reference planes. In the plug-in gait system, the measurement of knee valgus/varus angle was determined as the Euler angle of the shank segment reference frame relative to the thigh segment reference plane rotated in the order 1) flexion/extension, 2) valgus/varus, 3) internal/external rotation. The valgus/varus angle is the angle between the distal extension of the thigh axis and the shank axis. A positive angle indicates varus and a negative angle indicates valgus (Figure 1). Inter-joint distances were calculated as the linear distance in 3D between the corresponding lower limb joint centres of the right and left leg (i.e., distance between right and left knee joint centres) for the knee and ankle joints. Based on a frequency content analysis of the 3D coordinate data, marker trajectories were filtered using a Woltring Filter with a low-pass cut-off frequency of $10 \mathrm{~Hz}$ and stop-band frequency of $30 \mathrm{~Hz}$.

Figure 1 about here. 
Testing procedure.

The laboratory was set up with a rope fixed horizontally to act as a volleyball net at a height of $2.43 \mathrm{~m}$ for male subjects and $2.24 \mathrm{~m}$ for female subjects (height of a standard volleyball net). The net was placed $5 \mathrm{~cm}$ in front of and parallel to the adjacent force platforms. In addition to the net, a volleyball was suspended from the ceiling so that it was positioned $5 \mathrm{~cm}$ above the height of the net $(2.48 \mathrm{~m}$ for males and $2.29 \mathrm{~m}$ for females) and with the centre of the ball $10 \mathrm{~cm}$ in front of the line of the net (the other side of the net to where the subject (blocker) was standing). The ball was positioned vertically above the line separating the two force platforms. The jumping and landing task was made as realistic as possible by having subjects attempt to block an actual spike performed by an experienced volleyball player. At the start of each trial, the subject stood with each foot on a separate force plate. The subject then timed his/her blocking action in order to try to block the ball as it was spiked. The ball was spiked from the same suspended position in order to eliminate variation in the position and velocity of the ball. On landing, each foot landed on a separate force plate. Following appropriate warm up and practice, data was recorded for three successful trials for each subject.

\section{Data analysis.}

The angular displacement of the knee (mean data for right and left legs combined) in the frontal (valgus/varus) plane along with the inter-knee and inter-ankle distances were determined between initial ground contact and the end of landing, which was defined as, depending on which occurred later in each trial, either maximum knee 
flexion or maximum knee valgus angle. Time - series data were then normalised with respect to average trial time. Inter-joint distances were also normalised to height to account for gender differences in body size (expressed as percentage height, \%ht). Independent-samples t-tests were carried out on the angular displacement and interjoint data at initial ground contact, maximum and/or minimum values and range of motion to examine gender differences. Due to multiple t-tests (15) being carried out on samples taken from the same population, to reduce the chance of type I error, a Bonferroni adjustment was made to the alpha level.

\section{Results.}

Knee valgus/varus angle.

Figure 2 shows females contacted the ground in a slight valgus position (-ve values) which progressively increased between initial ground contact and the end of landing. Males, however, contacted the ground in a slight valgus position and moved into a slight varus position (+ve values) at the end of landing (Table 1 and Figure 2). The valgus angle at initial ground contact was not significantly different between males and females. However, the range of motion and the maximum valgus angle were significantly greater in females compared with males (Table 1 and Figure 2).

Table 1 about here.

Figure 2 about here. 
Inter knee and inter ankle displacements.

There was no significant difference in absolute or relative inter-knee distance at initial ground contact between males and females. The absolute minimum inter-knee distance was significantly longer for males than females but there was no significant difference in the relative minimum inter-knee distance between males and females. contact and the end of landing was significantly smaller for males than females. Figures 3 and 4).

Knee valgus/varus angle.

The results show that females exhibited significantly greater maximum knee valgus angle and significantly greater range of motion of knee valgus angle than males 
224 (Table 1 and Figure 2). This finding is supported by a number of previous studies 225 (Malinzak et al., 2001; Ford et al., 2003; Kernozek et al., 2005). However, the values reported in this study are different to previous results, particularly for females. For example, Kernozek et al. (2005) reported values of $0.7 \pm 6.9^{\circ}$ for males and $-24.9 \pm$ $8.5^{\circ}$ for females for maximum knee valgus angle (valgus -ve / varus +ve), compared with $0.6^{\circ} \pm 9.1$ for males and $-10.4^{\circ} \pm 7.7$ for females in this study. There are a number of possible reasons for these differences which include subjects' playing standard and task demands. For example, in Kernozek et al. (2005) the subjects used were recreational athletes whereas university athletes were used in this study. Also, the effect of opposition in the present study may have resulted in differing levels of conscious control over the landing manoeuvre than in the Kernozek et al. (2005) study which involved an unopposed drop landing task.

Since increased knee valgus angle during landing has been associated with increased risk of ACL injury (Boden et al., 2000; Olsen et al., 2004), the increased knee valgus angle exhibited by females compared with males during landing in the present study may suggest an increased risk of ACL injury in females compared with males. This in turn may be associated with the increased incidence of non-contact ACL injury in females compared with males.

Inter knee and inter ankle displacements.

The results of the inter-knee distances indicate that females' knees move significantly closer together and move through a greater absolute and relative distance during landing than males (Table 1), which is also reported by Ford et al. (2003). In the Ford 
et al. (2003) study, inter-knee distance was measured from markers placed on the lateral epicondyles of each femur, whereas in this study inter-knee distance was measured from estimated knee joint centres. Each estimated knee joint centre incorporates an offset equivalent to the sum of half the knee width and the marker radius. The knee joint centre is located as the offset from the marker located on the lateral epicondyle the femur in a direction perpendicular to the line from the hip joint centre to lateral epicondyle the femur marker. To compare the data from this study with that of Ford et al. (2003) the average knee offsets of $122.1 \mathrm{~mm}$ for males and $117.2 \mathrm{~mm}$ for females were applied to the Ford et al. (2003) data. The amended Ford et al. (2003) data for minimum inter-knee distance (males: $223.9 \mathrm{~mm} \pm 6$; females $203.8 \mathrm{~mm} \pm 6$ ) is similar to the results of the present study (males: $233.7 \mathrm{~mm} \pm 39.4$; females: $200.0 \mathrm{~mm} \pm 34.5$ ). However, the amended Ford et al. (2003) data for interknee displacement during landing (males: $53 \mathrm{~mm} \pm 5$; females: $73 \mathrm{~mm} \pm 5$ ) indicate greater displacement compared with the present results (males: $10.2 \mathrm{~mm} \pm 16.5$; females: $27.9 \mathrm{~mm} \pm 18.0$ ).

To our knowledge, no data has been reported for inter-ankle distances during twofooted landing manoeuvres. Therefore no comparisons can be made between the results of this study and previous studies. The inter-ankle results indicate that, after initial ground contact, the ankle joint linear motion was greater in males than females in both absolute and relative terms. From Table 1 and Figures 3 and 4 it can be seen that males' ankles are wider apart at initial ground contact and move together more quickly than in females for the first $40 \%$ of normalised contact time. Thereafter, the inter-ankle distance is similar in males and females. This is likely to be because the heels are in contact with the ground during this period. The movement patterns 
273 indicate that after the toes make contact with the ground, females' ankles move

vertically downward to the ground until the heels make contact, whereas for males, the ankles are brought in towards each other as the heels move down to the ground. When looking at the simultaneous linear motion of the knees and ankles on landing (Figures 3 and 4), a continuous inward movement of the ankles is shown by males and females, however, this inward movement of the ankles is greater in males than females. At the same time, the movement of the knees in males show an out - in out action resulting in minimum net movement. In contrast, the females' knees show continuous inward movement.

\section{Conclusions.}

During two-footed landing females exhibited significantly greater maximum valgus angle and range of motion of knee valgus angle than males. Furthermore, the absolute and relative inter-knee displacement during landing was significantly greater in females than males, whereas absolute and relative inter-ankle displacement during landing was significantly smaller in females than males. These results indicate that the greater knee valgus angle exhibited by females during landing may be influenced by gender differences in the combined linear movements of the knee and ankle joints rather than the knees in isolation. This greater knee valgus angle in females may increase the risk of ligament strain in females relative to males which may contribute to the gender difference in the incidence of non-contact ACL injury. Coaches should therefore incorporate exercises into training programmes to reduce the knee valgus angle in females during two-footed landing. Furthermore, these exercises should 
297 focus on the movement of the ankles as well as the knees in reducing knee valgus 298 during landing.

299 
Arendt, E. A., and Dick, R. (1995). Knee injury patterns among man and women in collegiate basketball and soccer. The American Journal of Sports Medicine, 23, 694701.

Bartold, S. J. (1997). Injury driven change to the fundamental design parameters of the Australian rules football boot. In Abstracts of the Australian conference of Science and Medicine in Sport (pp. 52-53). Canberra: Sports Medicine Australia.

Boden, B. P., Dean, G. S., Feagin, J. A., and Garrett, W. E. (2000). Mechanisms of anterior cruciate ligament injury. Orthopedics, 23, 573-578.

Chandy, T. A., and Grana, W. A. (1985). Secondary school athletic injury in boys and girls: a three-year comparison. Physician and Sports medicine, 13, 314-316.

Faegin, J. A. (1988). Isolated anterior cruciate injury. In J. A. Faegin, (Ed.), The crucial ligaments (pp. 15-23). New York: Churchill Livingstone.

Ferretti, A., Papandrea, P., Conteduca, F., and Mariani, P. P. (1992). Knee ligament injuries in volleyball players. The American Journal of Sports Medicine, 20, 203-207.

Ford, K. R., Myer, G. D., and Hewett, T. E. (2003). Valgus knee motion during landing in high school female and male basketball players. Medicine and Science in Sport and Exercise, 35, 1745-1750. Davidson, R. G. (1985). A survey of injuries to the anterior cruciate ligament of the knee in female basketball players. International Journal of Sports Medicine, 6, 314316. 
Griffin, L. Y., Angel, J., Albohm, M. J., Arendt, E. A., Dick, R. W., Garrett, W. E., Garrick, J. G., Hewett, T.E., Huston, L., Ireland, M. L., Johnson, R. J., Ben Kibler, W., Lephart, S., Lewis, J. L., Lindenfeld, T. N., Mandelbaum, B. R., Marchak, P., Teitz, C. C., and Wojtys, E.M. (2000). Noncontact anterior cruciate ligament injuries: risk factors and prevention strategy. Journal of the American Academy of Orthopaedic Surgeons, 8, 141-150.

Gwinn, D. E., Wilkens, J. H., McDevitt, E. R. Ross, G., and Kao, T. C. (2000). The relative incidence of Anterior cruciate ligament injury in men and women at the United States naval academy. The American Journal of Sports Medicine, 28, 98-102.

Hume, P. A. and Steele, J. R. (1997). Injury prevention strategies in netball: are Australian players heeding the advice? In Abstracts of the Australian conference of Science and Medicine in Sport (pp. 306-307). Canberra: Sports Medicine Australia.

Johnson, R. J. (1988). Prevention of anterior cruciate ligament injuries. In J. A. Faegin, (Ed.), The crucial ligaments (pp. 349-356). New York: Churchill Livingstone.

Kernozek, T. W., Torry, M. R., Van Hoof, H., Cowley, H., and Tanner, S. (2005). Gender differences in frontal plane and sagittal plane biomechanics during drop landings. Medicine and Science in Sport and Exercise, 37, 1003-1012.

Lindenfeld, T. N., Schmitt, D. J., Hendy, M. P., Mangine, R. E., and Noyes, F.R. (1994). Incidence of injury in indoor soccer. The American Journal of Sports Medicine, 22, 354-371.

Malinzak, R. A., Colby, S. M., Kirkendall, D. T., Yu, B., and Garrett, W. E. (2001). A comparison of knee joint motion patterns between men and women in selected athletic tasks. Clinical Biomechanics, 16, 438-445. 
Malone, T. R., Hardaker, W. T., Garrett, W. E. Feagin J.A., and Bassett F.H. (1993). Relationship of gender to anterior cruciate ligament injuries in intercollegiate basketball players. Journal of the Southern Orthopaedic Association, 2, 36-39.

McNair, P., Marshall, R., and Matherston, J. (1993). Important features associated with acute anterior cruciate injury. The New Zealand Medical Journal, 103, 537-539.

Miller, M. D. M., Cooper, D. E., and Warner, J. J. P. (1995). Review of sports medicine and arthroscopy. Philadelphia: W.B. Saunders.

Mykelbust, G., Maehlum, S., Engbretsen, L., Strand, T., and Solheim, E. (1997). Registration of cruciate ligament injuries in Norwegian top level team handball: a prospective study covering two seasons. Scandinavian Journal of Medicine and Science in Sports, 7, 289-292.

Olsen, O. E., Mykelbust, G., Engebretsen, L., and Bahr, R. (2004). Injury mechanisms for anterior cruciate ligament injuries in team handball: A systematic video analysis. The American Journal of Sports Medicine, 32, 1002-1012.

Otago, L., and Neal, R. J. (1997). Netball pivot landings- is there a correct way? In Abstracts of the Australian conference of Science and Medicine in Sport (pp. 262263). Canberra: Sports Medicine Australia.

Paulos, L. E. (1992). Why failures occur symposium: Revision ACL surgery. Presented at the American Orthopaedic Society for Sports Medicine. Eighteenth annual meeting. 6-9 July 1992, San Diego.

Smith, B. A., Livesay, G. A., and Woo, S. L. Y. (1988). Biology and biomechanics of the anterior cruciate ligament. Clinical Sports Medicine, 12, 637-666.

Watkins, J. (1999). Structure and Function of the Musculoskeletal System. Champaign: Human Kinetics. 
370 Woodland, L. H., and Francis, R. S. (1992). Parameters and comparisons of the 371 quadriceps angle of college-aged men and women in the supine and standing 372 positions. The American Journal of Sports Medicine, 20, 208-211. 


\section{List of figures.}

375 Figure 1. Knee valgus/varus angle: a) Markers placed on skin over bone landmarks.

b) Derived estimated joint centres and knee valgus/varus angle $\theta$.

Figure 2. Knee valgus/varus $\left(\theta_{\mathrm{v}}\right)$ between initial ground contact and the end of landing for males and females. The standard deviation at $1 \%$ normalised time 379 intervals in indicated by the vertical lines.

380 Figure 3. Absolute inter-knee $\left(d_{\mathrm{K}}\right)$ and inter-ankle $\left(d_{\mathrm{A}}\right)$ joint centre distances between 381 initial ground contact and the end of landing for males and females. Figure 4. Relative inter-knee $\left(d_{\mathrm{K}}\right)$ and inter-ankle $\left(d_{\mathrm{A}}\right)$ joint centre distances between initial ground contact and the end of landing for males and females. 
Table 1. Group mean results for valgus/varus (- varus; + valgus) angles, inter-knee and inter-ankle distances at initial ground contact (IC), maximum valgus angle $\left(\mathrm{MAX}_{\mathrm{VAL}}\right)$, maximum varus angle $\left(\mathrm{MAX}_{\mathrm{VAR}}\right)$, minimum distance (MIN) and range of motion during landing (ROM) (Mean \pm standard deviation).

\begin{tabular}{|c|c|c|c|c|c|}
\hline & & \multicolumn{2}{|c|}{ Males } & \multicolumn{2}{|c|}{ Females } \\
\hline & & Absolute & Relative & Absolute & Relative \\
\hline \multirow{4}{*}{$\begin{array}{c}\text { Valg/var } \\
\left({ }^{\circ}\right)\end{array}$} & IC & $-2.8 \pm 5.9$ & NA & $-1.6 \pm 2.8$ & NA \\
\hline & MAX $_{V A L}$ & $-2.9 \pm 7.9^{*}$ & NA & $-10.4 \pm 7.7^{\star}$ & NA \\
\hline & MAX $_{V A R}$ & $0.6 \pm 9.1$ & NA & $\mathrm{N} / \mathrm{A}$ & NA \\
\hline & ROM & $3.5 \pm 9.6^{*}$ & NA & $8.8 \pm 7.8^{*}$ & NA \\
\hline \multirow{3}{*}{$\begin{array}{l}\text { Inter-knee } \\
\text { distance } \\
\text { (mm / \%ht) }\end{array}$} & IC & $244.0 \pm 33.0$ & $13.9 \pm 1.9$ & $227.9 \pm 29.4$ & $13.8 \pm 1.8$ \\
\hline & MIN & $233.7 \pm 39.4^{*}$ & $13.3 \pm 2.2$ & $200.0 \pm 34.5^{\star}$ & $12.1 \pm 2.1$ \\
\hline & ROM & $10.2 \pm 16.5^{\star}$ & $0.6 \pm 0.9^{*}$ & $27.9 \pm 18.0^{\star}$ & $1.7 \pm 1.1^{*}$ \\
\hline \multirow{3}{*}{$\begin{array}{l}\text { Inter-ankle } \\
\text { distance } \\
\text { (mm / \%ht) }\end{array}$} & IC & $310.6 \pm 58.4$ & $17.7 \pm 3.3$ & $288.6 \pm 46.3$ & $17.5 \pm 2.8$ \\
\hline & MIN & $269.0 \pm 58.7$ & $15.3 \pm 0.9$ & $264.8 \pm 45.8$ & $16.1 \pm 2.8$ \\
\hline & ROM & $41.6 \pm 27.4^{*}$ & $2.4 \pm 1.6^{*}$ & $23.7 \pm 16.5^{*}$ & $1.4 \pm 1.0^{*}$ \\
\hline
\end{tabular}

*: Significant difference between males and females $(p<0.01)$. 